\title{
Os dilemas da Big Pharma
}

\section{| Reinaldo Guimarães |}

${ }^{1}$ Vice-presidente da Associação Brasileira das Indústrias de Química Fina, Biotecnologia e suas Especialidades (ABIFINA). Endereço eletrônico: reinaldo.guimaraes47@gmail.com

\begin{abstract}
We try never to forget that medicine is for the people. It is not for the profits. The profits follow, and if we have remembered that, they have never failed to appear. The better we have remembered it, the larger they have been.
\end{abstract} George Wilhelm Merck (1952)

We did not develop this medicine for Indians. We developed it for Western patients who can afford it. Bayer Chief Executive Officer Marijn Dekkers (2014)²

Que voltas o mundo deu no tempo que separa essas duas frases - tão opostas em seu conteúdo -, ambas ditas por presidentes de grandes companhias farmacêuticas hoje globais? Nesse intervalo, a indústria farmacêutica dos Estados Unidos e da Europa gerou o que hoje se denomina Big Pharma. O mercado farmacêutico global vale hoje cerca de um trilhão de dólares. Em 2013, as dez campeãs de vendas responderam por $45 \%$ desse mercado. Se agregarmos as dez seguintes, chegaremos a quase dois terços. Mas a despeito dessa potência econômica e do poder político que a ela se associa, a Big Pharma vive hoje a maior crise de sua história que, aliás, se iniciava naqueles anos da frase do Sr. Merck.

Os indicadores da crise são vários: em primeiro lugar, o enxugamento das folhas salariais. A compra da Wyeth pela Pfizer em 2009 gerou, até 2013, a demissão de mais de 51.000 empregados. A compra da Schering-Plough pela Merck, 24.000. $\mathrm{Na}$ AstraZeneca houve 13.500 demissões (Fierce Pharma, vários posts).

No que se refere às vendas, algum incremento se espera, mas nos mercados maduros que são a fonte da maior parte das receitas da Big Pharma, o crescimento 
será muito pequeno (EUA, entre 3\% e 5\% a.a.; e Europa, entre 1\% e 3\% a.a.). Para comparação, nos mercados emergentes nos quais outros atores estão atuando (em particular produtores locais), o crescimento esperado está acima de 10\% a.a. (IMS Health Market Prognosis). No Brasil, em 2013, alta de 16\% sobre o ano anterior. É verdade que, a partir de 2014, alguns medicamentos muito inovadores (em particular os novos tratamentos da hepatite C) chegaram ao mercado e fizeram com que os gastos com medicamentos nos EUA atingissem US\$ 374 bilhôes (crescimento de US\$ 43 bilhões em relação a 2013). Infelizmente, a maior parte do crescimento não respondeu a uma ampliação do acesso, mas aos preços estratosféricos dos produtos, o que contribuiu com cerca de metade desse crescimento. A ampliação do acesso respondeu por apenas U\$ 1 bilhão. Apenas para comparar, o gasto com medicamentos no Brasil em 2014 atingiu cerca de US\$ 20 bilhôes. Mas em compensação, o crescimento sustentado desses gastos na última década se deu essencialmente pela ampliação do acesso. Certamente uma diferença entre saúde como direito e saúde como mercadoria.

Os porquês da crise estão no lado da oferta, da demanda e nas instâncias que articulam uma e outra. Na oferta, o principal determinante tem sido o cruzamento da escassez no lançamento de novas moléculas inovadoras (new molecular entities, no jargão do FDA), com o término recente do período de proteção patentária de medicamentos altamente rentáveis.

No lado da demanda, tanto na Europa quanto nos EUA, o desemprego e o consequente empobrecimento das populações provocado pela crise de 2008 podem ter criado gargalos no acesso a medicamentos. As evidências são conflitantes. Em estudo contratado pela OMS, eles apontam para efeitos muito suaves em termos de diminuição de acesso a medicamentos (BUYSSE, 2010). Em outro estudo, sobre a crise econômica e o uso de serviços de saúde nos EUA, Canadá, Grã-Bretanha, França e Alemanha, constatam-se efeitos consistentes no sentido da diminuição do acesso (LUSARDI; SCHNEIDER; TUFANO, 2010). Os dois estudos mostram, ainda, que nos países com sistemas universais de saúde (ou com cobertura universal), a diminuição do acesso foi menor.

No campo das instâncias articuladoras entre oferta e demanda, tem sido parte constitutiva da crise o aumento do rigor dos critérios regulatórios pelas agências nacionais, bem como a atuação do Poder Judiciário na proteção dos sujeitos de pesquisa clínica e nas práticas comerciais das farmacêuticas, tema este ao qual 
voltarei mais adiante. Esses fatos, entre outros, têm como resultante o aumento exponencial de custos relativos aos novos projetos de medicamentos que chegam às fases finais de desenvolvimento.

O altamente complexo modelo de negócios da Big Pharma é resultado de um

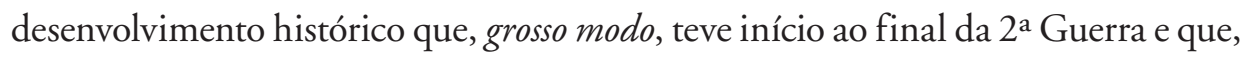
com razoável variação entre firmas e países, passou por três etapas (MALERBA, F.; ORSENIGO, 2002). A primeira delas (random screening) seguiu-se a descoberta, desenvolvimento e produção de antibióticos, começando com a penicilina. Nela, na medida em que nem as trajetórias metabólicas das patologias-alvo, nem os mecanismos de ação das substâncias eram adequadamente conhecidos, a busca por princípios ativos era fundada em tentativa e erro sobre centenas de amostras oriundas de inúmeras fontes. Em meados da década de 1970, o modelo de negócios modificou-se, com a articulação das descobertas da biologia celular, farmacologia, fisiologia, etc. Nesse novo modelo (rational drug design), os princípios ativos passam a ser imaginados e desenvolvidos a partir do conhecimento dos processos patológicos e da ação desses princípios sobre eles. $\mathrm{O}$ terceiro e atual modelo, que está em crise, foi instituído a partir dos desenvolvimentos biotecnológicos mais recentes vinculados a conhecimentos no campo da biologia molecular.

Importante mencionar que essa sucessão de modelos de negócios foi ancorada em oferta de conhecimento de base científica, como costuma ocorrer nos segmentos industriais intensivos em P\&D em sistemas de inovação maduros. Mas o modelo atual apresenta uma distinção importante face aos anteriores: nestes, a oferta de conhecimento esteve disponível ao tempo e à hora para ser absorvida pela indústria, enquanto agora parece haver algum descompasso. A promessa das "ômicas" (genômica, proteômica, etc.), a despeito da colossal quantidade de dinheiro a apoiá-las, em particular nos EUA, ainda não está respondendo às necessidades da indústria, pelo menos na velocidade e intensidade que a escassez de moléculas inovadoras estaria a exigir. Dentre os esforços governamentais destinados a adensar e apressar a oferta devida pelas instituiçôes de pesquisa às indústrias destacam-se as iniciativas de fomentar uma "pesquisa translacional" como modo canônico de fazer pesquisa em saúde nas universidades norteamericanas (GUIMARÃES, 2013). Colabora com essa interpretação o fato de que os novos blockbusters contra a hepatite $\mathrm{C}$ são moléculas relativamente simples, produzidas por síntese química e não em processos biotecnológicos. 
Quais têm sido as respostas das empresas à crise? A primeira foi uma onda de fusōes e aquisições de empresas cujo objetivo era adquirir os pipelines das empresas fundidas ou compradas. A segunda foi a decisão de diminuir a verticalização nas firmas, com o objetivo de compartilhar riscos com terceiros. A terceira foi a entrada no mercado de genéricos, que deixaram de ser "criminalizados" no marketing das companhias junto aos médicos. Além disso, radicalizaram-se as estratégias no terreno da propriedade intelectual visando fortalecer interesses comerciais, mesmo que em detrimento do interesse público. No Brasil, essa radicalização tem estado bastante ativa nos últimos anos e conta com a colaboração da nossa mais que permissiva Lei de Patentes. Houve, finalmente, uma radicalização nas estratégias comerciais. Aqui, foram rompidas as fronteiras da legalidade e nesse particular, a britânica GSK, a suíça Novartis e as americanas Johnson \& Johnson e Pfizer lideram e têm respondido por elas na justiça.

Com exceção da radicalização comercial e das ações visando estender o período de monopólio, as demais reações da Big Pharma são compreensíveis e, provavelmente, surtirão algum efeito. Entretanto, uma nova era de prosperidade para elas está refém de algo muito pouco controlável, que é a tradução de conhecimento científico no terreno da biologia molecular em moléculas candidatas a medicamentos realmente inovadores, como já houve no passado. Hoje isso não existe, pelo menos na intensidade necessária para um novo ciclo de crescimento sustentado.

Em 1951, o físico Robert Oppenheimer era o diretor do Laboratório de Energia Atômica em Los Alamos, no qual havia sido gerada a bomba atômica dos EUA. Escrevendo sobre essa trajetória, ele comentou que:

[...] as coisas que aprendemos [durante a $2^{a}$ Guerra] não são muito importantes. As coisas verdadeiramente novas foram aprendidas em 1890, 1905 e 1920 Los avanços da física], em todos os anos que conduziram à guerra, e nós pegamos essa árvore carregada de frutos maduros e a sacudimos e delas caíram o radar e as bombas atômicas... O espírito [durante a $2^{a}$ Guerra] era o de uma exploração frenética e um pouco inescrupulosa do conhecido; não o de uma tentativa sóbria e modesta de penetrar o desconhecido. ${ }^{3}$

Voltando ao campo dos medicamentos, talvez seja esse o grande dilema atual da Big Pharma. A falta dos frutos científicos maduros capazes de permitir o desenvolvimento de novos caminhos (e produtos). 


\section{Referências}

BUYSSE, I. M. Impact of the economic recession on the pharmaceutical sector. WHO Collaborating Centre For Pharmacoepidemiology \& Pharmaceutical Policy Analysis. February, 2010. Disponível em: http://apps.who.int/medicinedocs/documents/s17419e/ s17419e.pdf

GUIMARAES, R. Pesquisa Translacional: uma interpretação. Ciênc. saúde coletiva. Rio de Janeiro, v. 18, n. 6, p. 1731-1744, 2013. Disponível em: http://www.scielo.br/pdf/csc/ v18n6/24.pdf

LUSARDI, A.; SCHNEIDER, D.; TUFANO, P. The economic crisis and medical care usage. The Open Access Publication Server of the ZBW - Leibniz Information Centre for Economics. CFS Working Paper, n. 2010/10. Disponível em: http://www.econstor.eu/ bitstream/10419/43230/1/630564221.pdf

MALERBA, F.; ORSENIGO, L. innovation and market structure in the dynamics of the pharmaceutical industry and biotechnology: towards a history friendly model. Industrial and Corporate Change, v. 11, n. 4, p. 667-703, 2002. Disponível em: http://icc.oxfordjournals. org/content/11/4/667.full.pdf+html

STOKES, D.E. O quadrante de Pasteur: a ciência básica e a inovação tecnológica. Trad. José Emílio Maiorino. Campinas: EdUNICAMP, 2005.

\section{Notas}

${ }^{1}$ Disponível em: http://todayinsci.com/M/Merck_George/MerckGeorge-Quotations.htm

2 Disponível em: http://www.techdirt.com/articles/20140124/09481025978/big-pharma-ceo-we-develop-drugs-rich-westerners-not-poor.shtml

${ }^{3}$ First Annual Report of the National Science Foundation: 1950-1951 (apud STOKES, 2005, p. 35). 